\title{
Assessment of Length-Weight Relationship and Condition Factor of Nile Tilapia (Oreochromis Niloticus) in Cage and Open Waters in Winam Gulf of L. Victoria, Kenya
}

\author{
Steve Omari Ngodhe* and Okeyo Owuor-JB \\ Department of Environmental Science, Rongo University, Kenya
}

Submission: September 03, 2019; Published: November 08, 2019

*Corresponding author: Steve Omari Ngodhe, Department of Environmental Science, Rongo University P.O Box 103-40404, Rongo, Kenya

\begin{abstract}
The study aimed at investigating the difference in relationship between the Length and Weight together with the Fulton's condition factor of $O$. niloticus within the open waters (wild) and cages of the winam gulf of L.Victoria, Kenya. This relationship and the condition factor ' $\mathrm{K}$ ' were determined by taking the total length and weight of fish samples both from the cage and the open waters. The slope "b" of the regression analysis in both habitats revealed a positive allometric growth (3.16 and 3.09) for wild and cage respectively while the value of condition factor (K) for $O$. niloticus in wild and cage were found to be $1.44 \pm 0.1$ and $1.38 \pm 0.15$ respectively. Though $O$. niloticus performed well both in the wild and cage, there was a significant statistical difference in their health and general wellbeing. This was attributed to ecological differences between the two habitats. The assessment also showed that the culture of this Nile tilapia species in cages within winam gulf of L. Victoria can be economically sustainable if water quality parameters are properly monitored and point and non-point sources of pollution controlled.
\end{abstract}

Keywords: Length-Weight, Oreochromis niloticus, Wild, Cage, Winam gulf, L. Victoria, Kenya

\section{Background Information}

Information on some of the biological aspects of $O$. niloticus such as the relationship between the length and weight is very essential while doing a study on fish ecology. According to Morey et al. [1] the relationships between length and weight is a very powerful tool which can be applied to predict weight of fish from length measurements taken during the stock assessment and monitoring. During various stages in growth, fish can attain various forms of growth according to Riedel et al. [2]. They can either record an isometric growth, negative or positive allometric growth. Isometric growth is whereby the fish does not change the shape of its body as it continues to grow while negative allometric growth shows the fish becomes thinner as its body weight increases as opposed to a positive allometric growth which implies that the fish becomes relatively broader and fatter as its length increases. The relationship between length and weight in any given study is very vital biological study because it shows the change of two equations: growth-in-length and growth in-weight equations, which are very useful in fisheries management such as stock assessment models and it further allows the estimation of biomass from length observations by fisheries managers as stated by Moutopoulos \& Stergiou [3]. Arslan et al. [4] further reported that the value of the regression coefficient b (slope) in the Length-Weight relationship of fish is an important bioindicator in revealing the amount of food intake and the pattern in which the fish is growing which varies depending on the ecological conditions of the ecosystem.

The condition factor on the other hand according to Blackwell et al. [5] indicates the degree of well-being of the fish in their ecological niche as shown by length - weight factor. This factor is an indication of different environmental (Biotic and abiotic) and biological factors such as fitness, gonad development and the suitability of the environment with regard to the feeding condition. Higher value of the condition factor shows that the fish is healthy and growing positively. Khallaf et al. [6] indicated that the condition factor of fish can be influenced by different ecological and biological factors such as stress, sex, season, availability of feeds, and other water quality parameters. Fulton's condition factor, $\mathrm{K}$, can be calculated from the mathematical equation: $\mathrm{K}=(\mathrm{W} \times 100) /$ $\mathrm{L} 3$, where, $\mathrm{W}$ is the weight $(\mathrm{g})$ of fish and $\mathrm{L}$ is the total length $(\mathrm{cm})$ of fish; the factor 100 is normally used to bridge the gap between ' $\mathrm{K}$ ' and the value of one. It assumes isometric growth Cooney \& Kwak [7]. In case there is no isometric growth during fish stock assessment and monitoring, which rarely occurs, then $\mathrm{K}$ is likely to be different depending on the fish length. Comparison of the condition factor between different species is still a challenge since it's very difficult to register the same growth pattern which is a 
necessity for the comparison to be valid. To make comparisons possible and easier, Le Cren [8] introduced another aspect i.e. the relative condition factor, which takes care for the variation in form or condition with increase in length, and therefore estimates the deviation of an Individual fish from the mean weight for length in the respective sample: $\mathrm{Kn}=\mathrm{W} / \mathrm{aL}^{\mathrm{b}}$, where, $\mathrm{W}$ is the weight of fish and $\mathrm{aL}^{\mathrm{b}}$ is the mean weight predicted from relationship between the length and weight. , Le Cren [8] further revealed that the explanation of the fish condition factor is difficult and vulnerable to misinterpretation.

\section{Materials and Methods}

\section{Study area}

The assessment was done in winam gulf which is an extension of L. Victoria towards the inland areas of the former Nyanza province of Kenya (Figure 1). The extension is from East to West at approximately $100 \mathrm{~km}$ and also from North to South at about $50 \mathrm{~km}$. The gulf's shoreline covers about $550 \mathrm{~km}$. The Gulf is generally shallow; Hughes \& Hughes [9] recorded a maximum and mean depth of $68 \mathrm{~m}$ and $6 \mathrm{~m}$ respectively (Figure 1 ). The water tempera- ture at the surface of the entire gulf range between $23.50 \mathrm{C}$ and $29.0^{\circ} \mathrm{C}$. Currents which results from wind blowing from inshore to offshore influence water mixing in the gulf. During the study by Osumo [20], Water turbidity ranged between 35 to $155 \mathrm{~cm}$ and productivity is limited to the photic zone where photosynthetic organisms thrive [20]. Fish sampling for both cages and wild was done between January and September 2018. Cages were lifted and hand nets used to obtain the caged fish while wild fish were bought from the fishermen while they are still at the lake fishing. The team used engine boats to follow the fishermen onshore at monthly intervals for eight months. A total of 240 samples were sampled in cages and a similar numbers was also analyzed from the wild. Excess water from the samples was removed by a serviette before they were weighed in order to enhance accuracy and precision Anderson \& Gutreuter [10]. The measurements of both the weight and length were taken at the end of every sampling session. Weight and length of each individual fish sample was measured by using a very sensitive weighing balance and a measuring board respectively. The length was taken distance from the mouth-tip to the tip end of the tail fin.

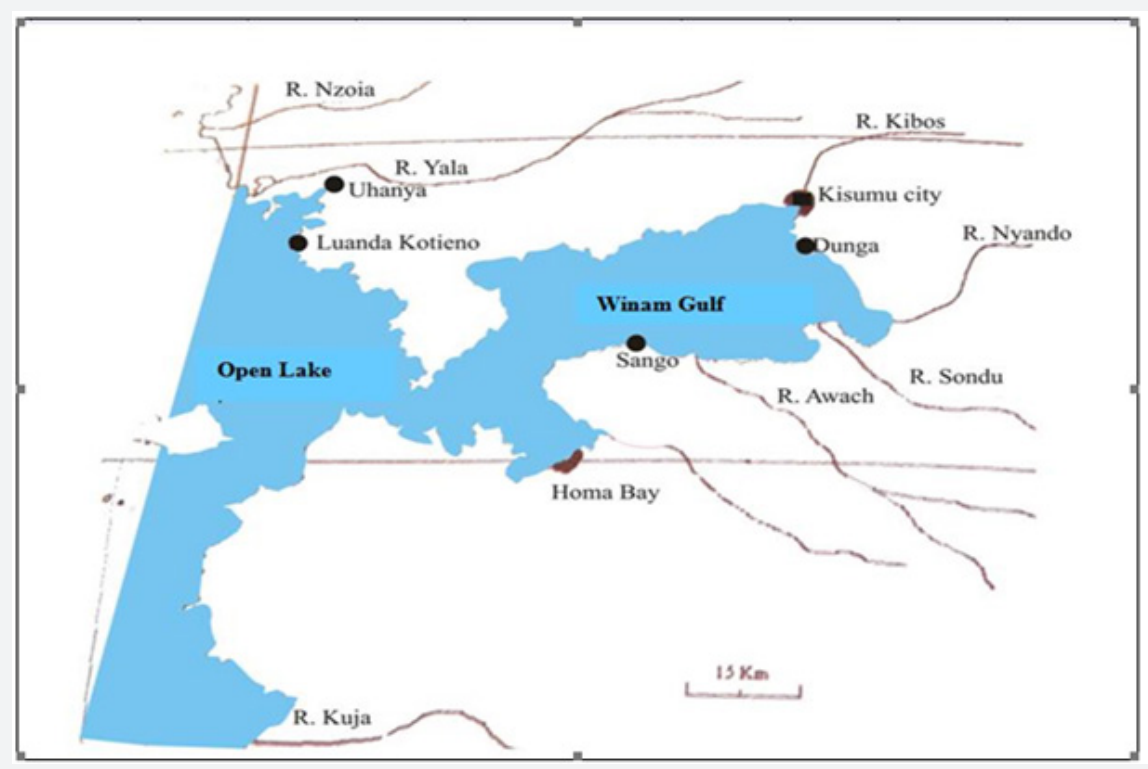

Figure 1: Winam Gulf map and its connection with the major water sources [20].

Data analysis: The length and weight relationship were analyzed by using the mathematical model $\mathrm{W}=\mathrm{aL}^{\mathrm{b}}$ as was proposed by Pauly [11].

\section{Whereby}

$$
\begin{aligned}
& \text { W= Fish weight }(\text { gram }) \\
& \text { L= Fish length }(\mathrm{cm}) \\
& \mathrm{a}=\text { intercept } \\
& \mathrm{b}=\text { slope }
\end{aligned}
$$

The above model was used to estimate ' $a$ ' and ' $b$ ' values. Isometric growth pattern usually occurs when the value ' $b$ ' is three (3) but when it's not equal to 3, then it automatically shows an- other growth pattern known as allometric, which can either be positive if ' $b$ ' is more than 3 or negative if it's less than 3.

The condition factor ' $K$ ' which indicates the degree of well-being of the fish in their ecological system was calculated by using the model, $\mathrm{K}=100 \mathrm{~W} / \mathrm{L}^{\mathrm{b}}$ according to Gomiero and Braga [12].

Whereby

$$
\begin{aligned}
& \mathrm{K}=\text { The Condition factor } \\
& \mathrm{W}=\text { Weight of fish in gram }(\mathrm{g}) \\
& \mathrm{L}=\text { Total length of fish in centimeters }(\mathrm{cm}) \\
& \mathrm{b}=\text { Figure derived from the } \mathrm{L}-\mathrm{W} \text { equation. }
\end{aligned}
$$


Results

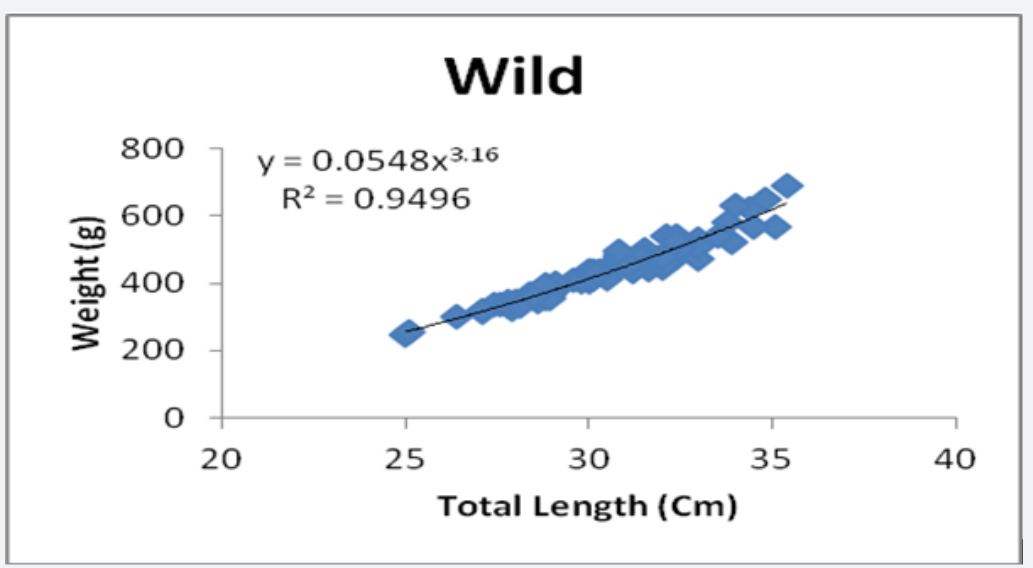

Figure 2: The relationship between the length and weight of $O$. niloticus in the open waters (wild)

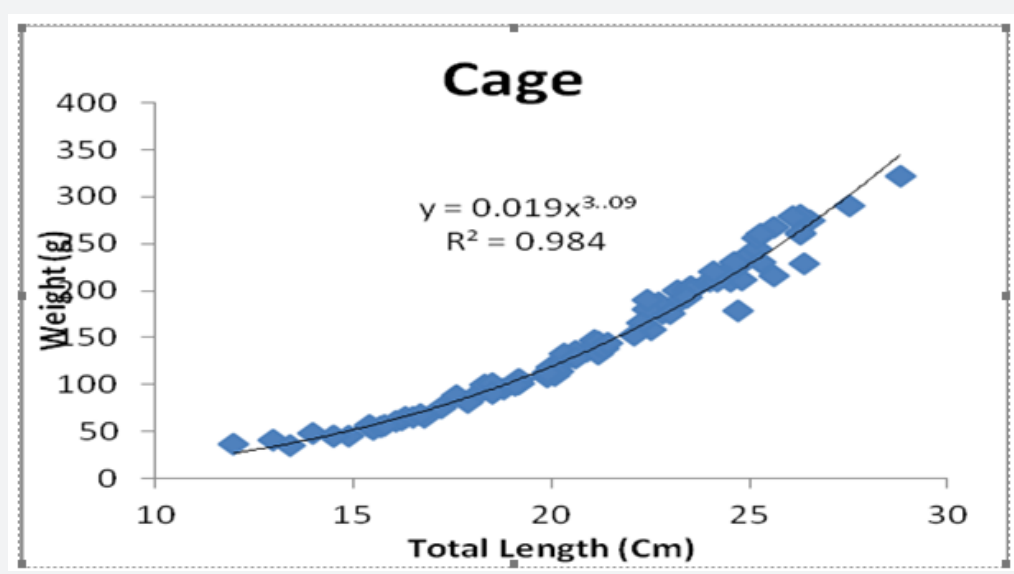

Figure 3: The relationship between the length and weight of $\mathrm{O}$. niloticus in the cage.

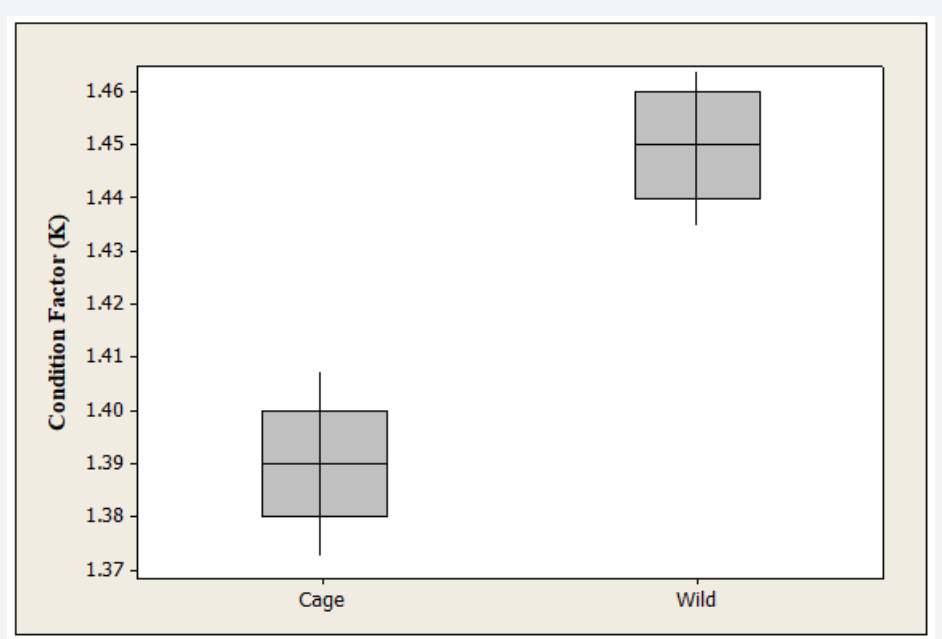

Figure 5: Condition factor $(\mathrm{K})$ of $O$. niloticus both in the wild and cage.

In this study the relationship between length and weight of $O$. niloticus in the wild revealed a positive allometric growth where it recorded a 'b' value of 3.16 (Figure 2). In the cages, the same growth was experienced i.e. positive allometric with a value of 'b' being 3.09 (Figure 3). The regression slope b was significantly different between the wild and cage samples (ANCOVA: $F=23.15$, 
$\mathrm{p}=0.002)$. On the other hand, the value of $\mathrm{K}$ for $O$. niloticus in both wild and cage were $1.44 \pm 0.1$ and $1.38 \pm 0.15$ respectively (Figure 4). There was also a significant statistical difference in mean ' $K$ ' values between the wild and cage samples ( $F=36.05, p=0.001)$.

\section{Discussion}

Both 0 . niloticus in the wild and cage showed a positive allometric growth in winam gulf, L. Victoria with a 'b' value of 3.16 and 23.09 respectively. According to Riedel et al. [2] this implies that it becomes relatively broader and fatter with the increase in length. This is also supported by Yongo [13] who also reported a positive allometric growth of $R$. argentea of L. Victoria, Kenya. However, Bala et al. [14] reported a negative allometric growth for Tilapia. zillii species in inland waters recording a ' $b$ ' value of 2.91. Limuwa et al. [15] during his study found a negative isometric growth in Opsaridium microlepis from Linthipe River in Central Malawi while Imam et al. [16] just like Bala et al. [14] also recorded a negative allometric growth recording a 'b' figure in Tilapia. zillii of 1.53 and 2.5 for rainy and hot seasons respectively while on the other hand Haruna [17] figures were 2.7 to 3.2. The values obtained for O.niloticus from this when compared with other similar studies shows that it falls within the range obtained by Haruna [17] but slightly higher than that obtained by Imam et al. [16]. The variation in growth pattern could be due to different ecological parameters during the study periods which comprises of several biotic and abiotic interactions depending on seasonality.

The mean condition factor for O.niloticus both in wild and cage was more than 1 with ' $K$ ' values of $1.44 \pm 0.1$ and $1.38 \pm 0.15$ respectively. Ibrahim et al. [18] recorded the ' $\mathrm{K}$ ' value of 1.94 for Tilapia. zillii in brackish water. The $\mathrm{K}$ values obtained in both cases were more than 1 which indicates that the fish was in healthy and biologically active. In comparison, the ' $\mathrm{K}$ ' value of $T$. zillii obtained by Imam et al. [16] recorded in inland waters ranged from 2.63-3.4 in hot and cold climate while on the other hand, [19] values ranged between 1.6603 to 2.0190 and 1.6354 to 2.134 . The variation which could be as a result of unfavourable physico-chemical water quality parameters such as temperature in ponds containing T. zilli which might have been higher due to the small surface area compared to a gulf which is bigger and therefore most of the heat from the sun get absorbed by soil and other particles which enters into the system through run-off. These spatio-temporal differences in temperature between this study and other studies might have affected other environmental variables such as dissolved oxygen, total dissolved solids, $\mathrm{pH}$, conductivity among others and that is why in the other studies, temperature seemed not to be within the optimal range for growth of tilapia.

Differences in regression value ' $b$ ' in the relationship (L-W) and condition factor value ' $K$ ' between the wild and cage samples could be as a result of the shadow effects caused by the cages as this block the heat from reaching directly into the water surface of the caged fish and therefore the temperature could have been lower in cages than in the wild. As stated, earlier temperature controls other ecological aspects of the habitat apart from the bi- ological aspects of fish and therefore the difference could be as a result of ecological differences. In cages, fish have very limited room to move as the stocking density is higher compared to fish in the wild which has a whole lake to move. This overcrowding could also have affected the general condition of the fish as the resources unlike in the wild were limited. Depth at which fish lives is also an important aspect which could have resulted into difference in growth rate and general fish condition in the two habitats. Fish in the wild feed from the deeper areas which are well aerated, less polluted and disturbed than the fish from the cages which feed from very few meters from the shore.

\section{Conclusion and Recommendation}

Based on the results obtained from this study, fish health and well-being can be achieved if water quality parameters are well managed. This study revealed a positive allometric growth both in the wild and the cages. The wild fish was better in overall condition than their caged counterpart and therefore water quality management must be maintained for maximum growth and yield in cage culture system in winam gulf. In order to enhance cage culture in the winam gulf of L. Victoria, Kenya more studies are still required especially on specific environmental parameters that directly or indirectly affect the fish-growth, nutrient levels. Information on nutritional requirement and economic suitability will be useful to primary stakeholders along the gulf and other investers who are involved in semi intensive and intensive aquaculture. The present study had a limited scope as it only focused on $O$. niloticus within the Winam gulf. This study therefore recommends that the future studies should include other species of fish in different aquatic ecological systems. The study further recommends a longer study period for assessment of the relationship between the length and weight together with the condition factors to take care of seasonality and other environmental variables.

\section{Acknowledgement}

The authors would like to thank the University of Eldoret, Kenya for provision of laboratory and technical support. We would also express our gratitude to the national research fund (NRF) for providing financial support.

\section{References}

1. Morey G, Moranta J, Massut E (2002) Weight-length relationships of littoral to lower slope fishes from the western Mediterranean. Fisheries Research Journal 62(1): 89-96.

2. Riedel R, Caskey LM, Hurlbert SH (2007) Length-weight relations and growth rates of dominant fishes of the Salton Sea: implications for predation by fish-eating birds. Lake and Reservoir Management 23(5): 528-535.

3. Moutopoulos DK, Stergiou KI (2002) Length-weight and length-length relationships of fish species from the Aegean Sea (Greece). Journal of Applied Ichthyology 18(3): 200-203.

4. Arslan M, Yıldırım A, Bektas S (2004) Length-weight relationship of brown trout, Salmo trutta (L), inhabiting Kan Stream, Coruh basin, north-eastern Turkey. Turkish Journal of Fisheries and Aquatic Sciences 48: 45-48. 
5. Blackwell BG, Brown ML, Willis DW (2000) Relative Weight (Wr): Status and current use in fisheries assessment and management'. Reviews in Fisheries Science 8: 1-44.

6. Khallaf E, Galal M, Athuman M (2003) The biology of Oreochromis niloticus in a polluted canal. Ecotoxicology 12(5): 405-416.

7. Cooney PB, TJ Kwak (2010) Development of standard weight equations for Caribbean and Gulf of Mexico Amphidromous fishes. North American Journal of Fisheries Management 30(5): 1203-1209.

8. Le Cren ED (1951) The length-weight relationship and seasonal cycle in gonad weight and condition in the perch (Perca avescens). Journal of Animal Ecology 20: 201-219.

9. Hughes RH, JR Hughes (1992) Lake Victoria: Lake Description. Directory of African Wildlife.

10. Anderson RO, Gutreuter SS (1985) Length-weight relationship and associated indices. American fisheries society, pp. 283-300

11. Pauly D (1993) Linear regressions in fisheries research. Journal of the Fisheries Research Board of Canada 30: 409-434.

12. Gomiero LM, Braga FMS (2005) The condition factor of fishes from two river basins in Sao Paulo state, Southeast of Brazil. Acta Scientiarum 27(1): 73-78.v

13. Yongo E (2016) Diet and some biological aspects of silver cyprinid, Rastrineobola argentea in lake victoria, Kenya (Unpl. Msc. Thesis presented to University of Eldoret, Kenya 23(3): 244-249.

This work is licensed under Creative Commons Attribution 4.0 License DOI: 10.19080/IJESNR.2019.21.556088
14. Bala U, Lawal I, Bolorunduro PI, Oniye SJ, Abdullahi SA, et al. (2009) Study of ichtyofauna of Daberam reservoir in Katsina State. Bayero Journal of Pure and Applied Sciences 2(2): 172-174.

15. Limuwa M, Kaunda EWH, Tembo FM, Msukwa AV, Jamu D (2014) Age and Growth of Lake Malawi Salmon Opsaridium microlepis (Günther, 1864) in the Linthipe River in Central Malawi Using Otoliths. World Applied Sciences Journal 32(4): 595-600.

16. Imam TS, Bala U, Balarabe ML, Oyeyi TI (2010) Length-weight relationship and condition factor of four fish species from Wasai Reservoir in Kano, Nigeria. African Studies 6: 125-130.

17. Haruna MA (2006) Length-weight relationship of four fish species chichlidae) from magaga lake, kano, Nigeria. Best Journal. 3: 109-111.

18. Ibrahim SM, Shalloof KA Sh, Salama HM (2008) Effect of Environmental Conditions of Abu-Zabal Lake on Some Biological, Histological and Quality Aspects of Fish, Cairo. Global Veterinaria 5(2): 257-270.

19. Mahomoud WF, Amin AMM, Elboray KF, Ramadhan AM, El-Halfawy MMKO (2011) Reproductive biology and some observation on the age, growth, and management of Tilapia zilli (1848) from Lake Timsah, Egypt. International Journal 3(2): 15-25.

20. Osumo (2001) Effects of water hyacinth on water quality of winam gulf, lake victoria. Final project report 2001.

Your next submission with Juniper Publishers will reach you the below assets

- Quality Editorial service

- Swift Peer Review

- Reprints availability

- E-prints Service

- Manuscript Podcast for convenient understanding

- Global attainment for your research

- Manuscript accessibility in different formats

( Pdf, E-pub, Full Text, Audio)

- Unceasing customer service

Track the below URL for one-step submission https://juniperpublishers.com/online-submission.php 